\title{
Naringin protects myocardial cells from doxorubicin-induced apoptosis partially by inhibiting the p38MAPK pathway
}

\author{
CHUN-YAN JIAN $^{1 *}$, HAN-BIN OUYANG $^{2 *}$, XIAN-HONG XIANG ${ }^{3 *}$, JIA-LI CHEN $^{2}$, YONG-XIN LI ${ }^{2}$, XIN ZHOU $^{2}$, \\ JIN-YANG WANG ${ }^{2}$, YANG YANG ${ }^{2}$, EN-YI ZHONG ${ }^{2}$, WEN-HUA HUANG ${ }^{2 * *}$ and HONG-WU ZHANG ${ }^{2 * *}$ \\ ${ }^{1}$ Department of Cardiology, Central People's Hospital of Zhanjiang, Zhanjiang, Guangdong 524000; \\ ${ }^{2}$ Department of Anatomy, Guangdong Provincial Key Laboratory of Construction and Detection in Tissue \\ Engineering, Southern Medical University, Guangzhou, Guangdong 510515; ${ }^{3}$ Department of Interventional \\ Radiology, The First Affiliated Hospital, Sun Yat-Sen University, Guangzhou, Guangdong 510080, P.R. China
}

Received May 19, 2016; Accepted April 6, 2017

DOI: $10.3892 / \mathrm{mmr} .2017 .7823$

\begin{abstract}
Doxorubicin (DOX) has been widely used to treat cancers as a first-line antitumor drug. However, it causes severe, irreversible, dose-dependent cardiotoxicity. To evaluate the protective effects of naringin (NRG) on cardiotoxicity, the authors investigated the molecular mechanism of the p38MAPK signaling pathway. H9c2 cells were treated for $24 \mathrm{~h}$ by using $5 \mu \mathrm{mol} / 1 \mathrm{DOX}$ without or with being pretreated by $1 \mu \mathrm{M}$ NRG for $150 \mathrm{~min}$ or by $3 \mu \mathrm{M} \mathrm{SB} 203580$ for $60 \mathrm{~min}$. Cell viability was detected by cell counting kit- 8 assay. Intracellular reactive oxygen species (ROS) levels were detected based on the oxidative conversion of 2',7'-dichlorfluorescein-diacetate (cell-permeable) to dichlorofluorescein (fluorescent). The expression of p38MAPK was determined by western blotting. The expression level of p-p38MAPK in H9c2 cells, which was significantly increased by exposure to $5 \mu \mathrm{M}$ DOX for $60 \mathrm{~min}$ $(\mathrm{P}<0.01)$, was significantly decreased by pretreatment with $1 \mu \mathrm{M}$ NRG for $150 \mathrm{~min}$ beforehand $(\mathrm{P}<0.01)$. The viability of $\mathrm{H} 9 \mathrm{c} 2$ cells pretreated for 150 min with $1 \mu \mathrm{M}$ NRG was significantly enhanced compared with that using DOX directly $(\mathrm{P}<0.01)$. Intracellular ROS levels were significantly reduced by being pretreated with $1 \mu \mathrm{M}$ NRG for 150 min or with $3 \mu \mathrm{M}$ SB203580 for $60 \mathrm{~min}$ before the cells were exposed to $5 \mu \mathrm{M}$ DOX. Collectively, NRG protected H9c2 cells against the cardiotoxicity induced by DOX through suppressing the
\end{abstract}

Correspondence to: Dr Hong-Wu Zhang or Professor Wen-Hua Huang, Department of Anatomy, Guangdong Provincial Key Laboratory of Construction and Detection in Tissue Engineering, Southern Medical University, 1023 Shatai South Road, Guangzhou, Guangdong 510515, P.R. China

E-mail: zhanghwu@mail2.sysu.edu.cn

E-mail: huangwenhua2009@139.com

${ }^{* * * *}$ Contributed equally

Key words: naringin, doxorubicin, cardiotoxicity, p38 mitogen-activated protein kinase, $\mathrm{H} 9 \mathrm{c} 2$ cells expression and activity of the p38MAPK pathway. The findings provided valuable evidence for the possible use of NRG to relieve DOX-induced cardiotoxicity.

\section{Introduction}

As a first-line antitumor drug, doxorubicin (DOX) has been widely used to treat cancers such as lymphomas, leukemias, solid tumors and soft-tissue sarcomas (1). Unfortunately, doxorubicin agent has severe, irreversible and dose-dependent cardiotoxicity $(2,3)$. Nowadays, DOX-induced cardiotoxicity has been attributed to mitochondrial impairment, oxidative stress, apoptosis and calcium overloading $(4,5)$, with oxidative stress as the main cause $(6,7)$. Reactive oxygen species (ROS) produced under oxidative stress finally induce cardiomyocyte apoptosis $(8,9)$.

p38 mitogen-activated protein kinase (p38MAPK) have been demonstrated to potentially serve a crucial role in DOX-induced cardiotoxicity $(10,11)$. The authors have previously reported this (12). As a member of the MAPK family, p38MAPK can be activated by chemical and physical stresses that promote growth and result in oxidative stress, apoptosis and vasoconstriction $(13,14)$.

Given that DOX-induced cardiotoxicity is mediated by oxidative stress, it may be helpful to use antioxidants for intervention. Recently, flavonoids have received considerable attention by being able to effectively scavenge free radicals and to protect against oxidative stress $(15,16)$. Besides exerting significant cardioprotective effects and lowering the risk of cardiovascular disease (17-19), flavonoids can also protect against DOX-induced cardiomyopathy and apoptosis of cardiomyocytes (20).

As a citrus flavonoid, naringin (4,5,7-trihydroxy-flavonone-7-rhamnoglucoside, NRG) is the major active constituent of tomentose pummelo peel that is a famous traditional Chinese medicine. Like most flavonoids, NRG has antioxidative (21), anti-inflammatory, hypolipidemic (22) and hypoglycemic effects (23). Hence, the authors speculated that NRG may protect against DOX-induced cardiotoxicity through antioxidative actions. However, it remains unknown whether NRG indeed can do so by suppressing the p38MAPK pathway. 
In the current study, a chemotherapy-induced cardiotoxicity model was established by treating $\mathrm{H} 9 \mathrm{c} 2$ cells with $5 \mu \mathrm{M}$ DOX (24). The study aimed to explore the following: i) The influence of NRG on DOX-induced cardiotoxicity; ii) the relationship between the p38MAPK signaling transduction pathway and oxidative stress in cardiotoxicity; iii) whether such cardiotoxicity can be alleviated by NRG through inhibiting the p38MAPK pathway.

\section{Materials and methods}

Materials. NRG $\geqq 95 \%$, DOX, SB203580, N-acetyl-L-cysteine (NAC), Hoechst 33258, rhodamine123 (Rh123) and 2',7'-dichlorofluorescin diacetate (DCFH-DA) were all bought from Sigma-Aldrich; Merck KGaA (Darmstadt, Germany). Cell Counting kit-8 (CCK-8) was provided by Dojindo Molecular Technologies, Inc. (Kumamoto, Japan). Caspase-3, t-p38 and p-p38 were purchased from Cell Signaling Technology, Inc. (Danvers, MA, USA). Fetal bovine serum (FBS) and Dulbecco's modified Eagle's medium (DMEM)-F12 were supplied by Gibco; Thermo Fisher Scientific, Inc. (Waltham, MA, USA). H9c2 cells were obtained from the Experimental Animal Center of Sun Yat-sen University (Guangzhou, China).

Cell culture. Embryonic rat cardiac cell line H9c2 was provided by the Experimental Animal Center of Sun Yat-sen University (Guangzhou, China) and cultured at $37^{\circ} \mathrm{C}$ in DMEM-F12 that was supplemented with $10 \% \mathrm{FBS}$ in an atmosphere comprising $5 \% \mathrm{CO}_{2}$.

Cell viability assay. Following being cultured in 96-well plates $\left(1 \times 10^{6}\right)$, the cells received different treatments, with the viability detected by CCK- 8 assay. CCK- 8 solution ( $10 \mu 1$, diluted by 1/10) was added into each well, following which the cells were further incubated for $2 \mathrm{~h}$ at $37^{\circ} \mathrm{C}$. The absorbance at $450 \mathrm{~nm}$ was read using Multiskan MK3 microplate reader (Thermo Fisher Scientific, Inc.). According to the following formula, the percentage of cell viability was calculated based on the average optical density (OD) of five wells from each group: Cell viability percentage $=\mathrm{OD}_{\text {treatment group }} / \mathrm{OD}_{\text {control group }} \mathrm{x} 100 \%$. The experiments were conducted in triplicate.

Detection of cell apoptosis by Hoechst 33258 staining. The apoptosis of $\mathrm{H} 9 \mathrm{c} 2$ cells was evaluated by Hoechst 33258 staining. Following different treatments, the cells were fixed for 10 min with $4 \%$ paraformaldehyde in phosphate-buffered saline (PBS), then washed by PBS three times, stained for $5 \mathrm{~min}$ by $5 \mathrm{mg} / \mathrm{l}$ Hoechst 33258, rinsed again by PBS and observed under BX50-FLA fluorescence microscope (Olympus Corporation, Tokyo, Japan). The viable cells emitted uniform blue fluorescence and presented normal nuclear sizes, but the apoptotic ones had fractured, condensed or distorted nuclei.

Detection of intracellular ROS levels. Intracellular ROS levels were detected by the oxidative conversion of DCFH-DA (cell-permeable) to dichlorofluorescein (DCF, fluorescent). Following being cultured in 24-well plates $\left(7 \times 10^{6}\right), \mathrm{H} 9 \mathrm{c} 2$ cells were treated differently and washed with PBS twice, into which serum-free medium containing $10 \mu \mathrm{M}$ DCFH-DA solution was thereafter added to incubate the cells for $60 \mathrm{~min}$ at $37^{\circ} \mathrm{C}$. They were then washed with PBS three times, DCF fluorescence in which was detected over the whole visual field by BX50-FLA fluorescence microscope (Olympus Corporation) connected with an imaging system. In addition, the mean fluorescence intensity (MFI) of four randomly selected fields was determined with ImageJ software (version, 1.41o; National Institutes of Health, Bethesda, MD, USA). ROS levels were represented by MFI of DCF.

Detection of mitochondrial membrane potential (MMP). MMP was detected by Rh123, a cell-permeable, fluorescent cationic dye preferentially entering mitochondria on the basis of a highly negative MMP. MMP depolarization leads to Rh123 loss from mitochondria, thus decreasing intracellular fluorescence. $\mathrm{H} 9 \mathrm{c} 2$ cells were herein cultured in 24 -well plates $\left(7 \times 10^{6}\right)$ and treated differently. Following addition of Rh123 (100 mg/l) into the culture medium, the cells were further incubated at $37^{\circ} \mathrm{C}$ for $45 \mathrm{~min}$ and observed under BX50-FLA fluorescence microscope (Olympus Corporation) connected with an imaging system. The MFI of Rh123 from four randomly selected fields, which was analyzed using ImageJ software, represented the level of MMP. The experiments were repeated three times.

Western blot analysis. Differently treated H9c2 cells were collected and lysed with ice-cold lysis solution $(10 \mathrm{mM}$ Tris- $\mathrm{HCl}$ (pH 7.4), $0.15 \mathrm{M} \mathrm{NaCl}, 5$ mM EDTA (pH 8.0), 1\% Triton X100), and the resulting homogenate was centrifuged for $10 \mathrm{~min}$ at $9,500 \mathrm{x} \mathrm{g}$ and $4^{\circ} \mathrm{C}$. Subsequently, total protein in the supernatant was quantified by using bicinchoninic acid assay protein assay kit (Sigma-Aldrich), resolved by $12 \%$ SDS-PAGE and transferred to a polyvinylidene difluoride membrane that was then blocked by $5 \%$ fat-free milk in TBS- $0.05 \%$ Tween 20 at room temperature for $1 \mathrm{~h}$, incubated overnight with t-p38MAPK (Sigma-Aldrich; cat no. M8177; dilution, 1:1,000), p-p38MAPK (Sigma-Aldrich; cat no. CS0430; dilution, 1:1,000) and caspase-3 antibodies (Sigma-Aldrich; cat no. C9598; dilution, 1:1,000) or horseradish peroxidase (HRP)-conjugated GAPDH antibody (Sigma-Aldrich; cat no. SAB2108668; dilution, 1:5,000) at $4^{\circ} \mathrm{C}$ under gentle agitation, and further incubated with a HRP-conjugated secondary antibody (Sigma-Aldrich; cat no. A9542; dilution, 1:3,000) at room temperature for $1.5 \mathrm{~h}$. Following being washed with TBS- $0.05 \%$ Tween three times, the membrane was developed by enhanced chemiluminescence (Sigma-Aldrich) and thereafter exposed to X-ray films that were scanned and determined by Image J software to quantify protein expression.

Statistical analysis. All experimental data were expressed as mean \pm standard error of the mean. Inter-group differences were analyzed with one-way analysis of variance and Fisher's Least Significant Difference by using SPSS software (version, 13.0; Chicago, IL, USA). $\mathrm{P}<0.05$ was considered to indicate a statistically significant difference.

\section{Results}

NRG inhibited DOX-induced cytotoxicity against H9c2 cells. Fig. 1A demonstrated that $24 \mathrm{~h}$ of exposure of $\mathrm{H} 9 \mathrm{c} 2$ cells to $5 \mu \mathrm{mol} / 1 \mathrm{DOX}$ induces obvious cytotoxicity $(\mathrm{P}<0.01)$ that 
reduces their viability, compared with the control group. The NRG concentration required to protect against DOX-induced cytotoxicity was calculated by performing a dose-response study in the presence of $0.1,1,10$ and $20 \mu \mathrm{mol} / 1 \mathrm{NRG}$ (Fig. 1A). The cytotoxic effects of DOX were significantly attenuated after $2 \mathrm{~h}$ of pretreatment by using $0.1-20 \mu \mathrm{mol} / 1$ NRG. Although $1 \mu \mathrm{mol} / 1 \mathrm{NRG}$ exerted the maximum effect, it alone hardly affected cell viability $(\mathrm{P}>0.05)$.

To find out the optimum treatment time of NRG for DOX-induced cytotoxicity, H9c2 cells were pretreated by $1 \mu \mathrm{mol} / 1 \mathrm{NRG}$ for 30,60, 90, 120, 150 and $180 \mathrm{~min}$ respectively prior to DOX exposure (Fig. 1B). Within 30-180 min after NRG pretreatment, the cell viability continuously increased and peaked at $150 \mathrm{~min}$. Therefore, $150 \mathrm{~min}$ of pretreatment with $1 \mu \mathrm{mol} / 1 \mathrm{NRG}$ was selected for subsequent experiments.

NRG inhibited DOX-induced increase in phosphorylated p38MAPK ( $p$-p38MAPK) expression. The expression of p-p38MAPK was detected by western blot analysis. As presented in Fig. 2, the expression level of p-p38MAPK, which is significantly elevated by $60 \mathrm{~min}$ of exposure of $\mathrm{H} 9 \mathrm{c} 2$ cells to DOX at $5 \mu \mathrm{M}(\mathrm{P}<0.01)$ compared with the control group, can be reduced by pretreatment with $1 \mu \mathrm{M}$ NRG for $150 \mathrm{~min}(\mathrm{P}<0.01$ compared with the control group). However, $1 \mu \mathrm{M}$ NRG alone barely affected the basal expression of p-p38MAPK $(\mathrm{P}>0.05)$.

NAC suppressed DOX-induced upregulation of p38MAPK. To elucidate whether NRG exerted inhibitory effects on DOX-induced increase in p-p38MAPK expression through antioxidative action, H9c2 cells were pretreated for $60 \mathrm{~min}$ with NAC (a ROS scavenger) at $1,000 \mu \mathrm{M}$ prior to $5 \mu \mathrm{M}$ DOX exposure. As presented in Fig. 3, pretreating the cells with NAC, similar to that of using NRG, significantly depresses DOX-induced upregulation of p-p38MAPK expression $(\mathrm{P}<0.01)$. Nevertheless, NAC alone hardly affected basal p-p38MAPK expression ( $P>0.05)$. Accordingly, NRG inhibited the DOX-induced increase in p-p38MAPK expression by resisting oxidation.

NRG and SB203580 attenuated DOX-induced cytotoxicity. The viability of $\mathrm{H} 9 \mathrm{c} 2$ cells was analyzed by detecting the reduction in percentage with CCK-8 assay. Such viability, which was decreased by $\sim 50 \%$ following $24 \mathrm{~h}$ of exposure to $5 \mu \mathrm{M}$ DOX, was significantly increased by preconditioning with $1 \mu \mathrm{M}$ NRG for $150 \mathrm{~min}(\mathrm{P}<0.01$ compared with the control group; Fig. 4). Moreover, preconditioning of the cells for 150 min by using SB203580 (a selective inhibitor of p38MAPK) at $3 \mu \mathrm{M}$ had similar cytoprotective effects to those of NRG, as suggested by the increase in cell viability. Either NRG or SB203580 alone failed to significantly affect the viability of $\mathrm{H} 9 \mathrm{c} 2$ cells $(\mathrm{P}>0.05)$. Therefore, the activation of p38MAPK was involved in the cytotoxicity against $\mathrm{H} 9 \mathrm{c} 2$ cells induced by DOX.

NRG and SB203580 mitigated DOX-induced cell apoptosis. The morphological changes during $\mathrm{H} 9 \mathrm{c} 2$ cell apoptosis were observed by Hoechst 203580 staining (Fig. 5). To evaluate the effects of NRG and SB203580 on the apoptosis induced by DOX, H9c2 cells were pretreated for 150 min with $1 \mu \mathrm{M} \mathrm{NRG}$ or for 60 min with $3 \mu \mathrm{M}$ SB203580 prior to DOX exposure.
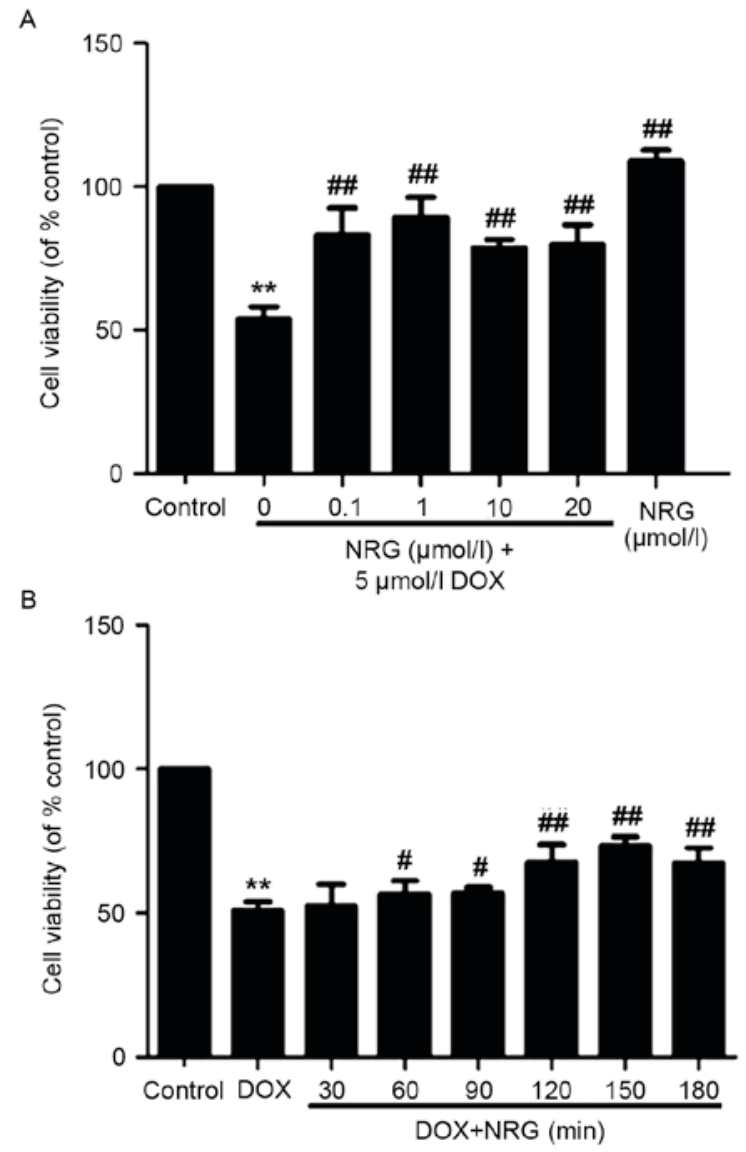

Figure 1. Influence of NRG on the viability of H9c2 cells. (A) Cells were pretreated with NRG at indicated concentrations for $120 \mathrm{~min}$ prior to exposure to $5 \mu \mathrm{mol} / 1 \mathrm{DOX}$ for $24 \mathrm{~h}$. (B) Cells were pretreated with $1 \mu \mathrm{mol} / 1 \mathrm{NRG}$ for indicated times prior to DOX exposure. CCK-8 assay was conducted to measure cell viability. The data are expressed as mean \pm standard error of the

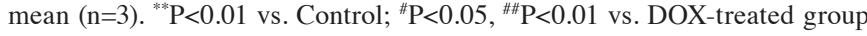
alone. NRG, naringin; DOX, doxorubicin.

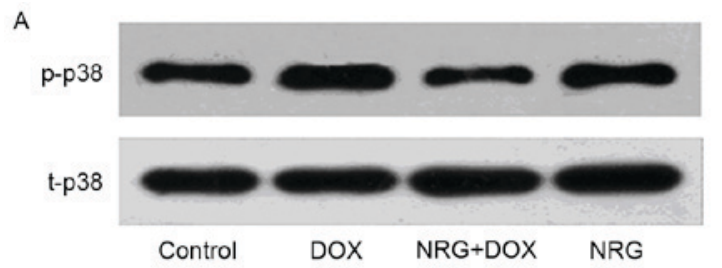

B

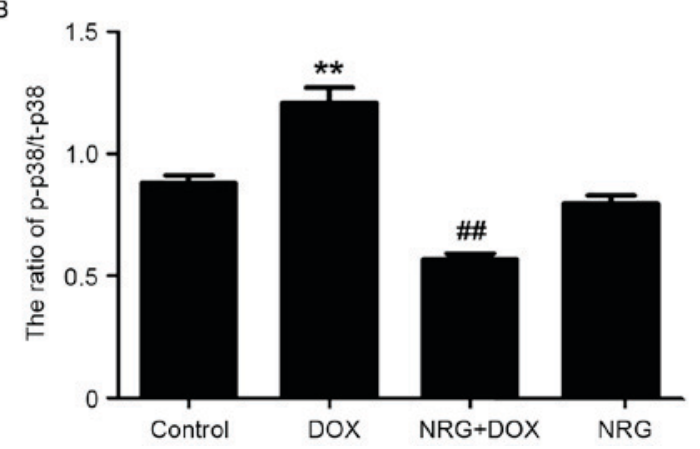

Figure 2. Influence of NRG on p-p38MAPK expression. (A) H9c2 cells were treated for $60 \mathrm{~min}$ with $5 \mu \mathrm{M}$ DOX in the presence or absence of $150 \mathrm{~min}$ of pretreatment by using $1 \mu \mathrm{M}$ NRG, and p38MAPK expression was detected by western blot analysis. (B) The data are expressed as mean \pm standard error of the mean $(\mathrm{n}=3) .{ }^{* *} \mathrm{P}<0.01$ vs. Control; ${ }^{\# \#} \mathrm{P}<0.01$ vs. DOX-treated group. NRG, naringin; DOX, doxorubicin; MAPK, mitogen-associated protein kinase. 


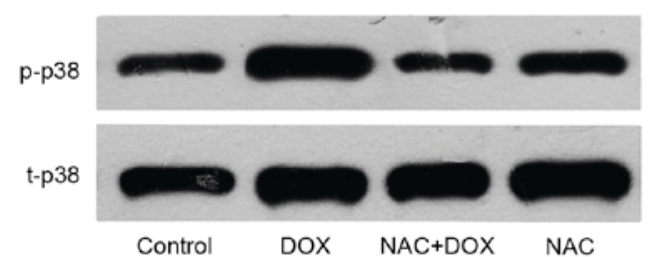

B

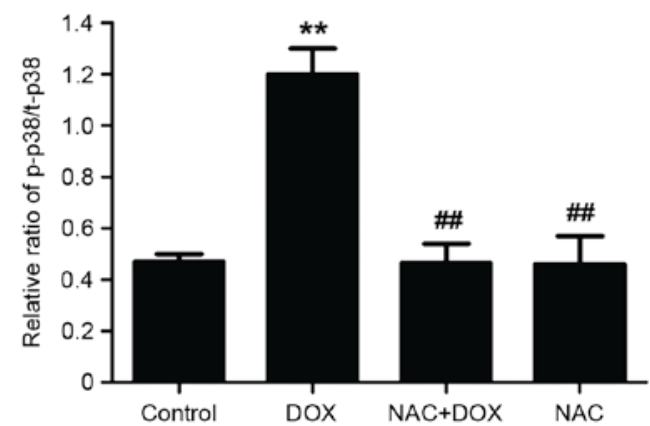

Figure 3. Roles of oxidative stress in DOX-induced upregulation of p-p38MAPK. (A) H9c2 cells were treated for 60 min with $5 \mu \mathrm{M}$ DOX in the presence or absence of 60 min of pretreatment by using 1,000 $\mu \mathrm{M} \mathrm{NAC}$, and p38MAPK expression was detected by western blot analysis. (B) The data are expressed as mean \pm standard error of the mean $(n=3) .{ }^{* *} \mathrm{P}<0.01 \mathrm{vs}$. Control; ${ }^{\# \#} \mathrm{P}<0.01$ vs. DOX-treated group. NAC, N-acetyl-L-cysteine; DOX, doxorubicin.

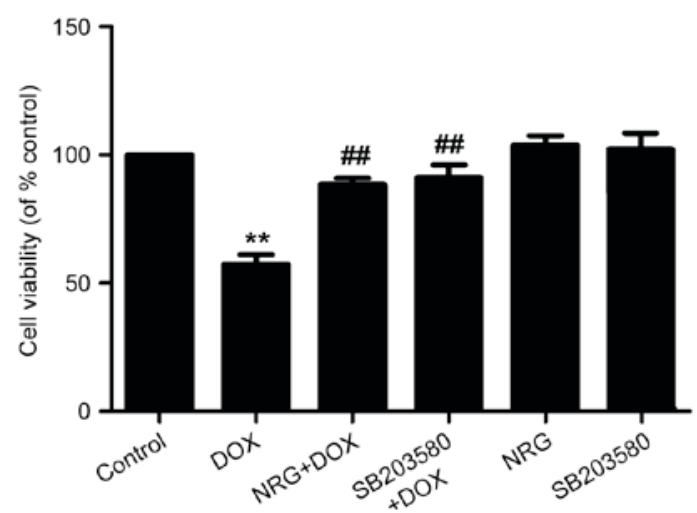

Figure 4. Effects of NRG and p38MAPK inhibitor on cytotoxicity induced by DOX. H9c2 cells were treated for $24 \mathrm{~h}$ with $5 \mu \mathrm{mol} / 1 \mathrm{DOX}$ in the presence or absence of $150 \mathrm{~min}$ of pretreatment by using $1 \mu \mathrm{M}$ NRG for or $60 \mathrm{~min}$ of pretreatment by using $3 \mu \mathrm{M}$ SB203580. The viability was then detected with Cell Counting kit- 8 assay. The data are expressed as mean \pm standard error of the mean $(\mathrm{n}=3) .{ }^{* *} \mathrm{P}<0.01$ vs. Control, ${ }^{\# \#} \mathrm{P}<0.01$ vs. DOX-treated group. NRG, naringin; DOX, doxorubicin.

As presented in Fig. 5B, $24 \mathrm{~h}$ of preconditioning with $1 \mu \mathrm{M}$ DOX induces typical apoptosis characteristics including chromatin condensation and nuclear shrinkage. The apoptotic cells with these characteristics decreased by preconditioning with NRG (Fig. 5C). In contrast, NRG alone almost had no visible effect on cell apoptosis (Fig. 5E). Furthermore, western blotting (Fig. 6A) indicated that $12 \mathrm{~h}$ of treatment by using $5 \mu \mathrm{M}$ DOX significantly upregulated the expression of cleaved caspase-3, an effector protease degrading most cellular targets that result in apoptotic cell death, with respect to the control group. However, the upregulation was markedly suppressed by preconditioning with $1 \mu \mathrm{M}$ NRG for $150 \mathrm{~min}$. Individual NRG at $1 \mu \mathrm{M}$ did not affect the expression of cleaved caspase-3
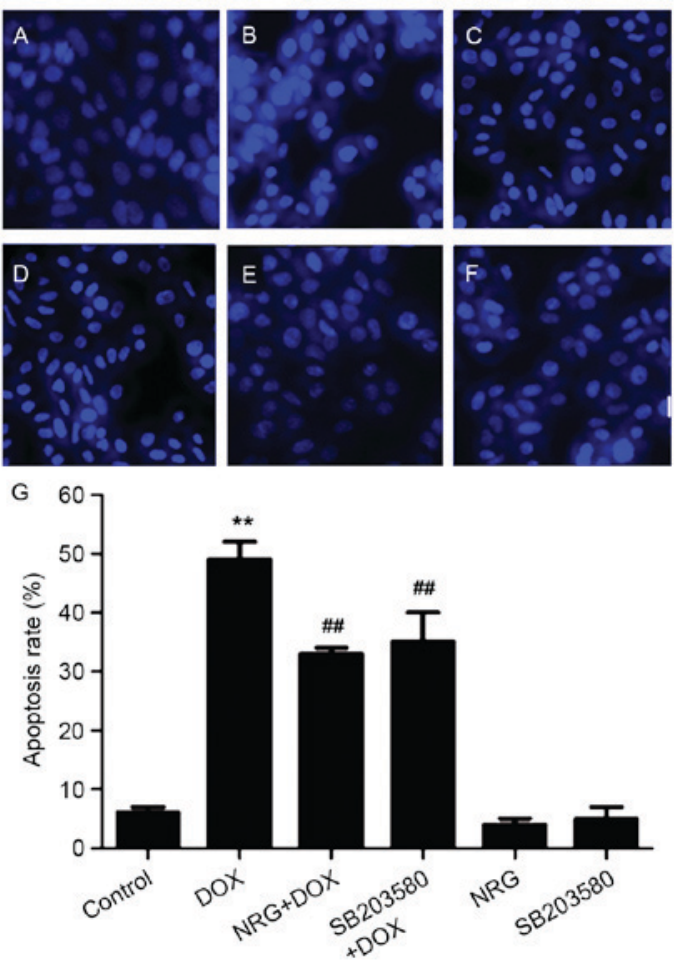

Figure 5. Effects of NRG and p38MAPK inhibitor on DOX-induced apoptosis of H9c2 cells. Following different treatments, H9c2 cells were stained by Hoechst 33258, the apoptosis of which was observed with fluorescence imaging. (A) Control group. (B) The cells were exposed for $24 \mathrm{~h}$ to DOX at $5 \mu \mathrm{M}$. (C) The cells were pretreated for 150 min by using $1 \mu \mathrm{M}$ NRG prior to $24 \mathrm{~h}$ of exposure to DOX at $5 \mu \mathrm{M}$. (D) The cells were treated for $60 \mathrm{~min}$ by using $3 \mu \mathrm{M} \mathrm{SB} 203580$ prior to $24 \mathrm{~h}$ of exposure to DOX at $5 \mu \mathrm{M}$. (E) The cells were treated for $150 \mathrm{~min}$ by using $1 \mu \mathrm{M}$ NRG and cultured for $24 \mathrm{~h}$. (F) The cells were treated for 60 min with $3 \mu \mathrm{M}$ SB203580 and cultured for 24 h. (G) Apoptotic rate was analyzed by the cell counter of ImageJ software. The data are expressed as mean \pm standard error of the mean $(n=3)$. Magnification, $\mathrm{x} 400 .{ }^{* *} \mathrm{P}<0.01$ vs. Control; ${ }^{\# /} \mathrm{P}<0.01$ vs. DOX-treated group. NRG, naringin; DOX, doxorubicin.

$(\mathrm{P}>0.05)$. These results indicated that $\mathrm{H} 9 \mathrm{c} 2$ cells were protected by NRG against apoptosis induced by DOX.

In order to examine whether p38MAPK activation was implicated in the apoptosis of H9c2 cells induced by DOX, they were pretreated for $60 \mathrm{~min}$ by $3 \mu \mathrm{M}$ SB2 203580 prior to 24 or $12 \mathrm{~h}$ of exposure to DOX at $5 \mu \mathrm{M}$ (to test the expression of cleaved caspase-3). As indicated in Figs. 5D and 6B, SB203580 pretreatment decreases both the number of apoptotic cells and the expression of cleaved caspse- 3 induced by DOX, suggesting that the activation of $\mathrm{p} 38 \mathrm{MAPK}$ participated in DOX-induced cytotoxicity. Individual SB203580 hardly affected cell apoptosis or caspase- 3 activation (Figs. $5 \mathrm{~F}$ and $6 \mathrm{~B}$ ).

All above findings suggested that the p38MAPK pathway was involved in the apoptosis of $\mathrm{H} 9 \mathrm{c} 2$ cells induced by DOX. Notably, NRG was able to protect $\mathrm{H} 9 \mathrm{c} 2$ cells against this kind of apoptosis by inhibiting the p38MAPK signaling pathway.

NRG and SB203580 depressed DOX-induced ROS generation. Following this, the authors assessed the antioxidative effects of NRG and whether p38MAPK activation contributed to the ROS overproduction induced by DOX through detecting the levels of intracellular ROS based on DCFH-DA staining. Following being treated for $24 \mathrm{~h}$ by using $5 \mu \mathrm{M}$ DOX, the levels 
A
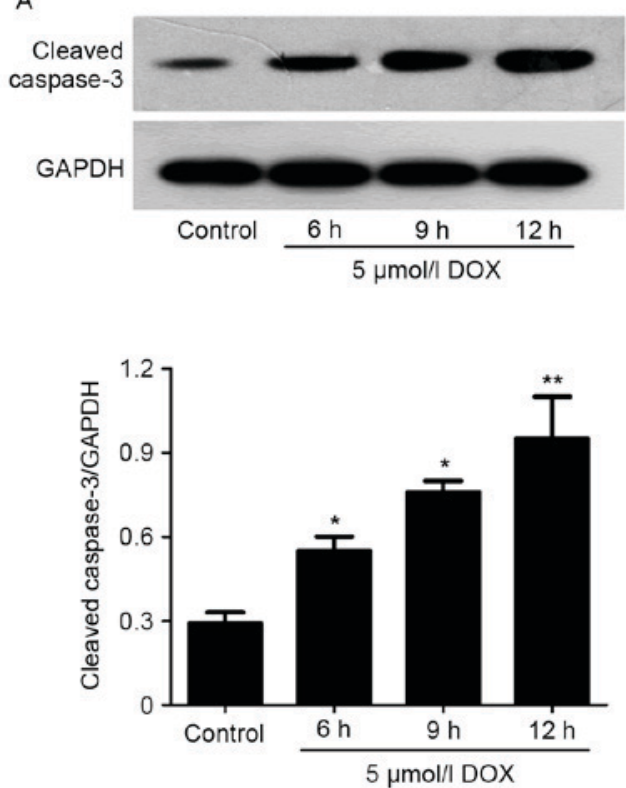

B
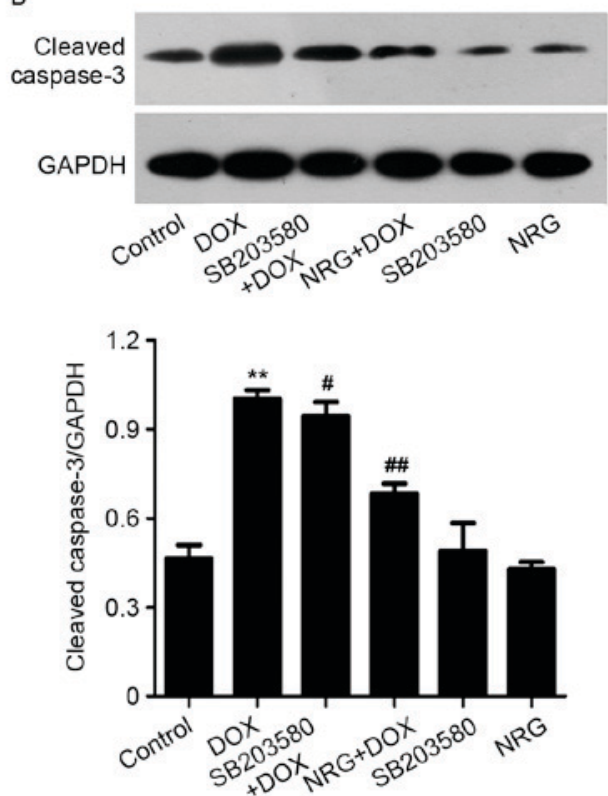

Figure 6. Western blot analyses. (A) Effects of DOX on the expression of cleaved caspase-3 after 6-12 h of H9c2 cell exposure to DOX at $5 \mu$ M. (B) Effects of NRG and p38MAPK inhibitor on DOX-induced increase in cleaved caspase-3 expression. The cells were treated for $12 \mathrm{~h}$ by using $5 \mu \mathrm{mol} / 1 \mathrm{DOX}$ in the presence or absence of 150 min of pretreatment by $1 \mu \mathrm{M}$ NRG or 60 min of pretreatment by $3 \mu \mathrm{M}$ SB203580. The data were quantified by ImageJ software using densitometric analysis and expressed as mean \pm standard error of the mean $(\mathrm{n}=3) .{ }^{*} \mathrm{P}<0.05,{ }^{* *} \mathrm{P}<0.01 \mathrm{vs}$. Control; ${ }^{\# \#} \mathrm{P}<0.01,{ }^{\#} \mathrm{P}<0.05$ vs. DOX-treated group, NRG, naringin; DOX, doxorubicin.

of intracellular ROS in H9c2 cells significantly increased $(\mathrm{P}<0.01$; Fig. 7). Interestingly, $150 \mathrm{~min}$ of pretreatment by $1 \mu \mathrm{M} \mathrm{NRG}$ or $60 \mathrm{~min}$ of pretreatment by $3 \mu \mathrm{M} \mathrm{SB} 203580$ significantly reduced the levels of intracellular ROS, revealing the antioxidative effects of NRG and the involvement of the p38MAPK pathway in the oxidative stress induced by DOX. Similar to the control group, the cells treated with $1 \mu \mathrm{M}$ NRG or $3 \mu \mathrm{M}$ SB203580 individually emitted weak DCF fluorescence.

$N R G$ and SB203580 depressed DOX-induced disruption of $M M P$. It is well-documented that $(8,9,25)$ disruption of MMP was involved in the cardiotoxicity induced by DOX, so the authors examined the effects of NRG and a p38MAPK inhibitor on DOX-disrupted MMP. As presented in Fig. 8B, following being treated for $24 \mathrm{~h}$ by $5 \mu \mathrm{M}$ DOX, the mitochondrial number of $\mathrm{H} 9 \mathrm{c} 2$ cells is evidently decreased, which reduced the uptake of Rh123, thereby verifying the loss of MMP. However, such loss was relieved by $150 \mathrm{~h}$ of preconditioning by $1 \mu \mathrm{M} \mathrm{NRG}$ (Fig. 8C), suggesting that NRG managed to protect the cells against the mitochondrial damage induced by DOX. Similarly, pretreatment with SB203580 significantly depressed the loss of MMP induced by DOX $(\mathrm{P}<0.05$; Fig. 8D), suggesting that NRG provided mitochondrial protection by inhibiting p38MAPK expression. Alone, neither NRG nor SB203580 had any effect on MMP (both $\mathrm{P}>0.05$ ).

\section{Discussion}

Although NRG has antioxidative (26), anti-inflammatory (27), antimicrobial (28) and anticancer activities (29), whether it can protect against the cardiotoxicity induced by DOX remains unclear. Thus, the authors herein first assessed the effects of 0.1 ,
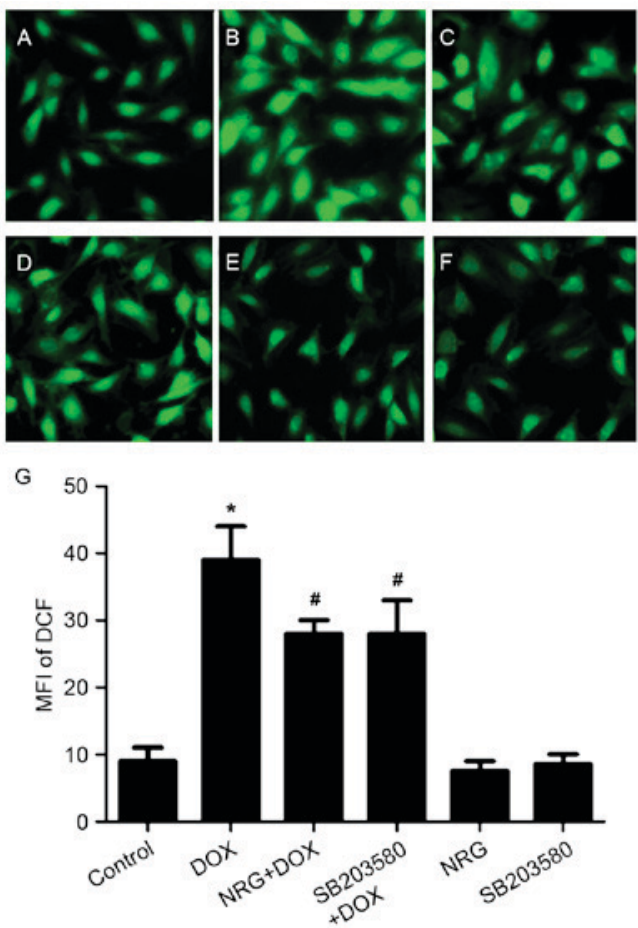

Figure 7. Immunofluorescence staining of reactive oxygen species in differently treated H9c2 cells. (A) Control group. (B) The cells were exposed for $24 \mathrm{~h}$ to DOX at $5 \mu \mathrm{M}$. (C) The cells were pretreated for $150 \mathrm{~min}$ by NAG at $1 \mu \mathrm{M}$ before $24 \mathrm{~h}$ of exposure to DOX at $5 \mu \mathrm{M}$. (D) The cells were pretreated for $60 \mathrm{~min}$ by $3 \mu \mathrm{M} \mathrm{SB} 203580$ before $24 \mathrm{~h}$ of exposure to DOX at $5 \mu \mathrm{M}$. (E) The cells were treated for $150 \mathrm{~min}$ by $1 \mu \mathrm{M} \mathrm{NRG}$ and cultured for $24 \mathrm{~h}$. (F) The cells were treated for 60 min by $3 \mu \mathrm{M} \mathrm{SB} 203580$ and cultured for $24 \mathrm{~h}$. (G) Quantified MFI of DCF in A-F by Image J software. The data are expressed as mean \pm standard error of the mean $(n=3)$. Magnification, $x 400$. ${ }^{*} \mathrm{P}<0.05$ vs. Control; ${ }^{\#} \mathrm{P}<0.05$ vs. DOX-treated group. DOX, doxorubicin; NAC, N-acetyl-L-cysteine; NRG, naringin; DCF, dichlorofluorescein; MFI, mean fluorescence intensity. 

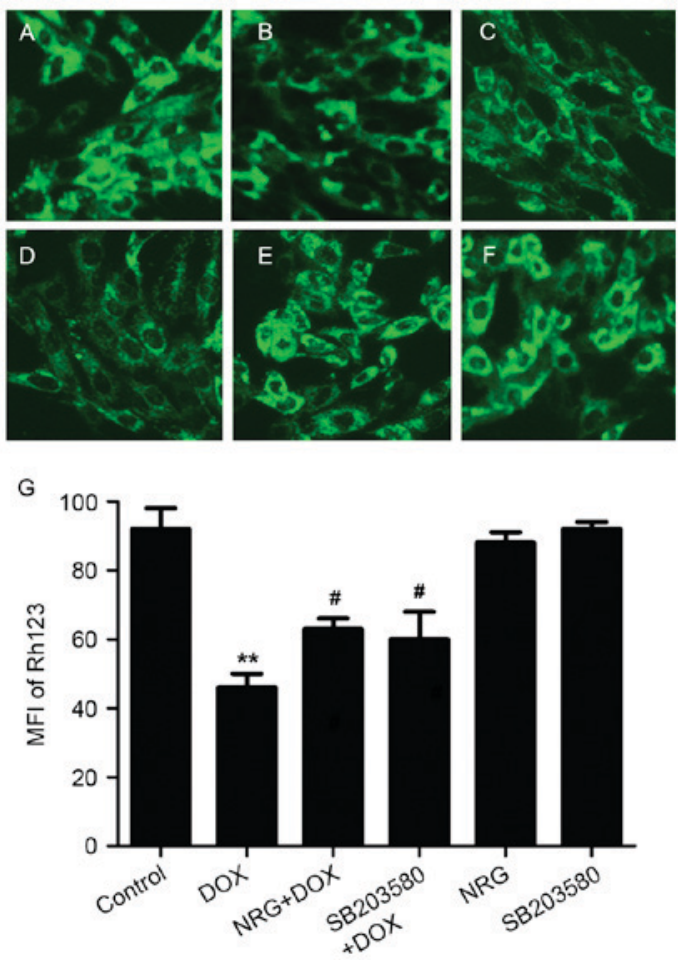

Figure 8. Immunofluorescence staining of mitochondrial membrane potential in differently treated H9c2 cells. (A) Control group. (B) The cells were treated for $24 \mathrm{~h}$ by DOX at $5 \mu \mathrm{M}$. (C) The cells were pretreated for $150 \mathrm{~min}$ by $1 \mu \mathrm{M}$ NRG before $24 \mathrm{~h}$ of exposure to DOX at $5 \mu \mathrm{M}$. (D) The cells were pretreated for $60 \mathrm{~min}$ by $3 \mu \mathrm{M} \mathrm{SB} 203580$ before $24 \mathrm{~h}$ of exposure to DOX at $5 \mu \mathrm{M}$. (E) The cells were treated for $30 \mathrm{~min}$ by $1 \mu \mathrm{M} \mathrm{NRG}$ and cultured for $24 \mathrm{~h}$. (F) The cells were treated for $60 \mathrm{~min}$ by $3 \mu \mathrm{M} \mathrm{SB} 203580$ and cultured for 24 h. (G) Quantified MFI of Rh123 in A-F by Image J software. The data are expressed as mean \pm standard error of the mean $(n=5) .{ }^{* *} \mathrm{P}<0.01$ vs control; " $\mathrm{P}<0.05$ vs. DOX-treated group. DOX, doxorubicin; NRG, naringin; MFI, mean fluorescence intensity; Rh123, rhodamine123.

1, 10 and $20 \mu \mathrm{mol} / 1 \mathrm{NRG}$ on DOX-induced cardiotoxicity after $15,30,60,90,120$ and 180 min of treatment, respectively. In a previous study of the authors, it was recently established that a DOX-induced cardiomyocyte injury model, made by exposing H9c2 cells to DOX at $5 \mu \mathrm{mol} / 1$ (30), manifested as decreased cell viability, increased apoptosis, p-p38MAPK expression, ROS production and MMP loss. Likewise, in the present study, preconditioning with different concentrations $(0.1,1,10$ and $20 \mu \mathrm{mol} / \mathrm{l}$ ) of NRG decreased the loss of cell viability (Fig. 1A). Above all, $1 \mu \mathrm{mol} / 1 \mathrm{NRG}$ significantly increased cell viability by attenuating DOX-induced cytotoxicity, and the protective effects reached optimum at $150 \mathrm{~min}$. The findings indicated that NRG significantly alleviated DOX-induced cytotoxicity against $\mathrm{H} 9 \mathrm{C} 2$ cells.

The cardioprotective effects of NRG and relevant mechanisms have attracted increasing attention in recent years. Rajadurai et al (31) reported that pretreating isoproterenol-induced rats with NRG significantly enhanced the activities of NADH, tricarboxylic acid cycle enzymes and cytochrome c oxidase. Subsequently, they found that, in the heart of ISO-induced rats, NRG significantly augmented the activities of catalase, mitochondrial SOD, GST and GPx together with the mitochondrial level of GSH. Hence, the protective effects of NRG contributed to antioxidative, membrane-stabilizing and free radical-scavenging properties. In addition, the authors have demonstrated that NRG exerted protective effects on diabetic cardiomyopathy through inhibition of NF- $\kappa \mathrm{B}$ (32). Therefore, it is of great significance to clarify the mechanisms by which NRG protects against DOX-induced injuries in cardiomyocytes. Guo et al (12) reported that p38MAPK participated in the cardiotoxicity induced by DOX. Presumably, inhibition of p38MAPK contributes to the protective effects of NRG on this cardiotoxicity, which was supported by the findings in the present study. Pretreating H9c2 cells with NRG before DOX exposure significantly reduced DOX-induced elevation in p-p38MAPK expression. Notably, pretreatment with NRG allowed cardioprotection similarly to the specific p38MAPK inhibitor SB203580, manifesting as a decreased number of apoptotic cells, increased cell viability, ROS accumulation and MMP dissipation. Thus, p38MAPK activation predominantly controlled the cardioprotective action of NRG. Moreover, pretreatment with the ROS scavenger NAC inhibited the expression and activity of p38MAPK like NRG did. This novel finding suggested that NRG suppressed the activation of p38MAPK probably by resisting oxidation. Kanno et al (33) indicated that NRG attenuated the oxidative stress induced by cytosine arabinoside by enhancing the activities of antioxidant enzymes and inhibiting ROS generation simultaneously. Kang et al (11) indicated that metallothionein has an antioxidative capacity, which suppresses p38MAPK by inhibiting cardiomyocyte apoptosis induced by DOX (11). Clearly, the current results are well supported by the previous literature.

The activation of caspase- 3 is a vital step in DOX-induced apoptosis $(1,34)$ Maejima et al (35) reported that cardiomyocytes underwent apoptosis typified by caspase-regulated proteolytic degradation, activation of caspase and cleavage of internucleosomal DNA, leading to the progression of myocardial dysfunction upon heart failure. Accordingly, inhibiting caspase-3 expression may pave the way for preventing and treating the cardiomyopathy induced by DOX $(36,37)$. To this end, the authors explored the relationship between p38MAPK and caspase- 3 in the cardioprotective effect of NRG. Similar to NRG, SB203580 significantly inhibited cleaved caspase-3 expression (Fig. 6B), implying that NRG protected against DOX-induced cell apoptosis through inhibiting the activation of p38MAPK.

To the best of the authors' knowledge, the present study is the first time that NRG was indicated to protect $\mathrm{H} 9 \mathrm{c} 2$ cells against the cardiotoxicity induced by DOX through inhibiting the expression and activity of p38MAPK. Particularly, the antioxidative property of NRG may contribute to suppressing the expression of p38MAPK induced by DOX. In addition, the authors provide novel evidence for indicating that $\mathrm{p} 38 \mathrm{MAPK}$ participates in cell apoptosis, ROS generation and loss of MMP in DOX-induced injuries. In conclusion, NRG is potentially eligible for treating or preventing DOX-associated cardiotoxicity.

\section{Acknowledgements}

The present study was supported by the National Natural Science Foundation of China (grant no. 61427807), the Natural Science Foundation of Guangdong Province in China (grant nos. 2014A030310035 and 2016A030313602), and the Fujian Province Introduction of Major Research and Development Institution Funding Project (grant no. 2012I2004). 


\section{References}

1. Bai J, Ma M, Cai M, Xu F, Chen J, Wang G, Shuai X and Tao K: Inhibition enhancer of zeste homologue 2 promotes senescence and apoptosis induced by doxorubicin in p53 mutant gastric cancer cells. Cell Prolif 47: 211-218, 2014.

2. Hrdina R, Gersl V, Klimtová I, Simůnek T, Machácková J and Adamcová M: Anthracycline-induced cardiotoxicity. Acta Medica (Hradec Kralove) 43: 75-82, 2000.

3. Scully RE and Lipshultz SE: Anthracycline cardiotoxicity in long-term survivors of childhood cancer. Cardiovasc Toxicol 7: 122-128, 2007.

4. Ludke AR, Al-Shudiefat AA, Dhingra S, Jassal DS and Singal PK: A concise description of cardioprotective strategies in doxorubicin-induced cardiotoxicity. Can J Physiol Pharmacol 87: 756-763, 2009.

5. Alkreathy H, Damanhouri ZA, Ahmed N, Slevin M, Ali SS and Osman AM: Aged garlic extract protects against doxorubicin-induced cardiotoxicity in rats. Food Chem Toxicol 48 951-956, 2010

6. Xu MF, Tang PL, Qian ZM and Ashraf M: Effects by doxorubicin on the myocardium are mediated by oxygen free radicals. Life Sci 68: 889-901, 2001

7. Simůnek T, Stérba M, Popelová O, Adamcová M, Hrdina R and Gersl V: Anthracycline-induced cardiotoxicity: Overview of studies examining the roles of oxidative stress and free cellular iron. Pharmacol Rep 61: 154-171, 2009.

8. Singal PK, Li T, Kumar D, Danelisen I and Iliskovic N: Adriamycin-induced heart failure: Mechanism and modulation. Mol Cell Biochem 207: 77-86, 2000.

9. Spallarossa P, Garibaldi S, Altieri P, Fabbi P, Manca V, Nasti S, Rossettin P, Ghigliotti G, Ballestrero A, Patrone F, et al: Carvedilol prevents doxorubicin-induced free radical release and apoptosis in cardiomyocytes in vitro. $\mathbf{J}$ Mol Cell Cardiol 37: 837-846, 2004

10. Zhu W, Zou Y, Aikawa R, Harada K, Kudoh S, Uozumi H, Hayashi D, Gu Y, Yamazaki T, Nagai R, et al: MAPK superfamily plays an important role in daunomycin-induced apoptosis of cardiac myocytes. Circulation 100: 2100-2107, 1999.

11. Kang YJ, Zhou ZX, Wang GW, Buridi A and Klein JB: Suppression by metallothionein of doxorubicin-induced cardiomyocyte apoptosis through inhibition of p38 mitogen-activated protein kinases. J Biol Chem 275: 13690-13698, 2000.

12. Guo RM, Xu WM, Lin JC, Mo LQ, Hua XX, Chen PX, Wu K, Zheng DD and Feng JQ: Activation of the p38 MAPK/NF- $\kappa B$ pathway contributes to doxorubicin-induced inflammation and cytotoxicity in H9c2 cardiac cells. Mol Med Rep 8: 603-608, 2013.

13. Li J, Zhao Z, Liu J, Huang N, Long D, Wang J, Li X and Liu Y: $\mathrm{MEK} / \mathrm{ERK}$ and $\mathrm{p} 38 \mathrm{MAPK}$ regulate chondrogenesis of rat bone marrow mesenchymal stem cells through delicate interaction with TGF-beta 1/Smads pathway. Cell Prolif 43: 333-343, 2010.

14. Force T and Bonventre JV: Growth factors and mitogen-activated protein kinases. Hypertension 31: 152-161, 1998.

15. Hussein RH and Khalifa FK: The protective role of ellagitannins flavonoids pretreatment against $\mathrm{N}$-nitrosodiethylamine induced-hepatocellular carcinoma. Saudi J Biol Sci 21: 589-596, 2014.

16. Lohani M, Ahuja M, Buabeid MA, Dean S, Dennis S, Suppiramaniam V, Kemppainen B and Dhanasekaran M: Anti-oxidative and DNA protecting effects of flavonoids-rich Scutellaria lateriflora. Nat Prod Commun 8: 1415-1418, 2013

17. Huxley RR and Neil HA: The relation between dietary flavonol intake and coronary heart disease mortality: A meta-analysis of prospective cohort studies. Eur J Clin Nutr 57: 904-908, 2003.

18. Bast A, Kaiserová H, den Hartog GJ, Haenen GR and van der Vijgh WJ: Protectors against doxorubicin-induced cardiotoxicity: Flavonoids. Cell Biol Toxicol 23: 39-47, 2007.

19. Du Y, Guo H and Lou H: Grape seed polyphenols protect cardiac cells from apoptosis via induction of endogenous antioxidant enzymes. J Agric Food Chem 55: 1695-1701, 2007.
20. Bagchi D, Sen CK, Ray SD, Das DK, Bagchi M, Preuss HG and Vinson JA: Molecular mechanisms of cardioprotection by a novel grape seed proanthocyanidin extract. Mutat Res 523-524: 87-97, 2003.

21. Kong X, Qiu D, Ye X, Bao J, Sui Z, Fan J and Xiang W: Physicochemical and crystalline properties of heat-moisture-treated rice starch: Combined effects of moisture and duration of heating. J Sci Food Agric 95: 2874-2879, 2015.

22. Ahmad SF, Attia SM, Bakheet SA, Zoheir KM, Ansari MA, Korashy HM, Abdel-Hamied HE, Ashour AE and Abd-Allah AR: Naringin attenuates the development of carrageenan-induced acute lung inflammation through inhibition of NF- $k b$, STAT3 and pro-inflammatory mediators and enhancement of I $\mathrm{BB} \alpha$ and anti-inflammatory cytokines. Inflammation 38: 846-857, 2015.

23. Choe SC, Kim HS, Jeong TS, Bok SH and Park YB: Naringin has an antiatherogenic effect with the inhibition of intercellular adhesion molecule-1 in hypercholesterolemic rabbits. J Cardiovasc Pharmacol 38: 947-955, 2001.

24. Ali MM and El Kader MA: The influence of naringin on the oxidative state of rats with streptozotocin-induced acute hyperglycaemia. Z Naturforsch C 59: 726-733, 2004.

25. Wang XY, Yang CT, Zheng DD, Mo LQ, Lan AP, Yang ZL, Hu F, Chen PX, Liao XX and Feng JQ: Hydrogen sulfide protects H9c2 cells against doxorubicin-induced cardiotoxicity through inhibition of endoplasmic reticulum stress. Mol Cell Biochem 363: 419-426, 2012.

26. Ozyürek M, Akpinar D, Bener M, Türkkan B, Güçlü K and Apak R: Novel oxime based flavanone, naringin-oxime: Synthesis, characterization and screening for antioxidant activity. Chem Biol Interact 212: 40-46, 2014.

27. Liu J, Mao W, Ding B and Liang CS: ERKs/p53 signal transduction pathway is involved in doxorubicin-induced apoptosis in H9c2 cells and cardiomyocytes. Am J Physiol Heart Circ Physiol 295: H1956-H1965, 2008.

28. Ozcelik B, Kartal M and Orhan I: Cytotoxicity, antiviral and antimicrobial activities of alkaloids, flavonoids, and phenolic acids. Pharm Biol 49: 396-402, 2011.

29. Tan TW, Chou YE, Yang WH, Hsu CJ, Fong YC and Tang CH: Naringin suppress chondrosarcoma migration through inhibition vascular adhesion molecule- 1 expression by modulating miR-126. Int Immunopharmacol 22: 107-114, 2014.

30. Rajadurai $M$ and Prince PS: Preventive effect of naringin on cardiac mitochondrial enzymes during isoproterenol-induced myocardial infarction in rats: A transmission electron microscopic study. J Biochem Mol Toxicol 21: 354-361, 2007.

31. Rajadurai M and Prince PS: Naringin ameliorates mitochondrial lipid peroxides, antioxidants and lipids in isoproterenol-induced myocardial infarction in Wistar rats. Phytother Res 23: 358-362, 2009.

32. Li W, Wang C, Peng J, Liang J, Jin Y, Liu Q, Meng Q, Liu K and Sun H: Naringin inhibits TNF-a induced oxidative stress and inflammatory response in HUVECs via Nox4/NF- $\mathrm{B}$ and PI3K/Akt pathways. Curr Pharm Biotechnol 15: 1173-1182, 2014.

33. Kanno S, Tomizawa A, Hiura T, Osanai Y, Shouji A, Ujibe M, Ohtake T, Kimura K and Ishikawa M: Inhibitory effects of naringenin on tumor growth in human cancer cell lines and sarcoma S-180-implanted mice. Biol Pharm Bull 28: 527-530, 2005.

34. Takemura G and Fujiwara H: Doxorubicin-induced cardiomyopathy from the cardiotoxic mechanisms to management. Prog Cardiovasc Dis 49: 330-352, 2007.

35. Maejima Y, Adachi S, Morikawa K, Ito H and Isobe M: Nitric oxide inhibits myocardial apoptosis by preventing caspase-3 activity via S-nitrosylation. J Mol Cell Cardiol 38: 163-174, 2005.

36. Christiansen $\mathrm{S}$ and Autschbach R: Doxorubicin in experimental and clinical heart failure. Eur J Cardiothorac Surg 30: 611-616, 2006.

37. Chen M, Fan ZC, Liu XJ, Deng JL, Yang Q and Huang DJ: Cell transplantation with a catheter-based approach: An efficient method for the treatment of heart failure with multiple lesions. Cell Prolif 39: 471-477, 2006 